\title{
Imaging Soft-tissue Sarcomas of the Head and Neck: A Tertiary Soft-tissue Sarcoma Unit Experience
}

\author{
ALAA ALSADIK JALY ${ }^{1}$, KHIN THWAY ${ }^{1,2}$, PHILIP TOUSKA ${ }^{3}$, ANITA WALE ${ }^{1}$, \\ AISHA MIAH ${ }^{1,2}$, CYRUS KERAWALA $^{1}$, FRANCESCO RIVA ${ }^{1}$, ELEANOR MOSKOVIC ${ }^{1}$, \\ ROBIN L. JONES ${ }^{1,2}$, DIRK STRAUSS ${ }^{1}$, DERFEL AP DAFYDD ${ }^{1}$ and CHRISTINA MESSIOU ${ }^{1,2}$ \\ ${ }^{1}$ The Royal Marsden Hospital, London, U.K.; \\ ${ }^{2}$ The Institute of Cancer Research, London, U.K.; \\ ${ }^{3}$ Guy's and St Thomas' Hospital, London, U.K.
}

\begin{abstract}
Background/Aim: To describe imaging features of head and neck soft-tissue sarcomas. Patients and Methods: Patients with a diagnosis of head and neck sarcoma between 2011 and 2015 were reviewed. Results: There were a total of 62 patients ( 24 female; median age $=60$ years). Most common sarcomas were angiosarcoma, undifferentiated pleomorphic sarcoma and sarcoma not otherwise specified. They were most commonly located in cranial and neck superficial soft tissues. Average tumour size at presentation was $45 \mathrm{~mm}$. One patient had metastasis at presentation (rhabdomyosarcoma); two had nodal disease (rhabdomyosarcoma and angiosarcoma) and two tumours contained calcification (chondrosarcoma and synovial sarcoma). Four arose after prior radiotherapy. Conclusion: Unlike the more common diagnosis of squamous cell carcinoma, the majority of head and neck sarcomas present as large, solitary, superficial masses without lymph node enlargement. Identification of these features on imaging should raise suspicion of a sarcoma diagnosis, particularly in the setting of previous irradiation or genetic susceptibility.
\end{abstract}

Soft-tissue sarcomas (STSs) are rare tumours of mesenchymal origin accounting for $1 \%$ of adult cancer cases (1). Although the majority occur in the trunk and extremities, head and neck sarcomas represent an estimated $15 \%$ of sarcomas in adults (2-4).

STSs vary in grade, behaviour and metastatic potential and often manifest as painless, enlarging masses (5). Their management differs from that of more common head and neck

Correspondence to: Dr. Christina Messiou, Department of Radiology, The Royal Marsden Hospital, Fulham Rd, London, SW3 6JJ, U.K. Tel: +44 2086613216, Fax: +44 2086610846, e-mail: Christina.Messiou@rmh.nhs.uk

Key Words: Soft tissue, sarcoma, cancer, head and neck, imaging. malignancies which are mostly squamous cell carcinomas. STS of the head and neck is increasingly recognised as a distinct clinical challenge with disproportionate risk of local recurrence (6). This is reflected in the eighth edition of the TNM staging which now provides staging which is site-specific for STS of the head and neck (7).

An appreciation of characteristic imaging features may trigger early suspicion for a diagnosis of STS, facilitating early referral to specialist sarcoma centres. Optimum management for primary non-metastatic disease is surgical resection at a sarcoma centre, often with radiotherapy to reduce local recurrence. Chemotherapy is usually reserved for non resectable or metastatic disease. Paediatric-type rhabdomyosarcoma and Ewing sarcoma have a clear treatment schedule which includes induction chemotherapy.

The rarity and variable appearance of STSs present a diagnostic challenge that can result in delays or incorrect management. There is very little published information on the specific radiological appearance of head and neck sarcomas. We therefore present the imaging features of head and neck STSs based on experience from referrals to our tertiary Soft-Tissue Sarcoma Unit.

\section{Patients and Methods}

Institutional Review Board approval was obtained (SE480). The Royal Marsden Sarcoma Unit prospectively maintained STS database was searched for patients with a histological diagnosis of STS of the head and neck during the period January 2011 - May 2015. Patients without computerised tomography (CT) or magnetic resonance imaging (MRI) of the primary tumour and staging $\mathrm{CT}$ or fluorodeoxyglucose positron-emission tomography (FDG PET)/CT of the chest, abdomen and pelvis at presentation were excluded. The Electronic Patient Record was interrogated for patient date of birth, gender and history of previous radiotherapy to the head and neck. For patients with a diagnosis of malignant peripheral nerve sheath tumour (MPNST), a history of neurofibromatosis 1 (NF1) was also documented. The local picture archiving and communication system was used to review the imaging and the 


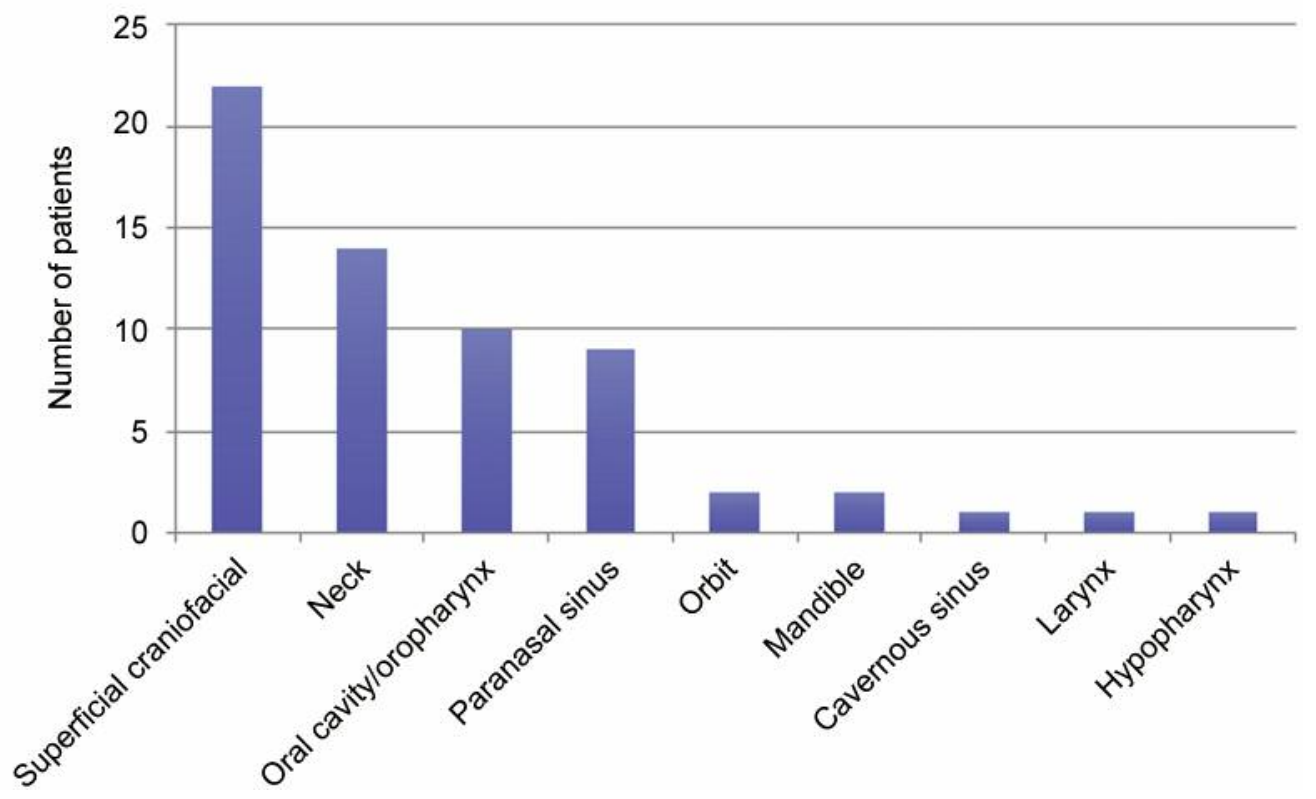

Figure 1. Location of soft-tissue sarcomas in the head and neck.

A

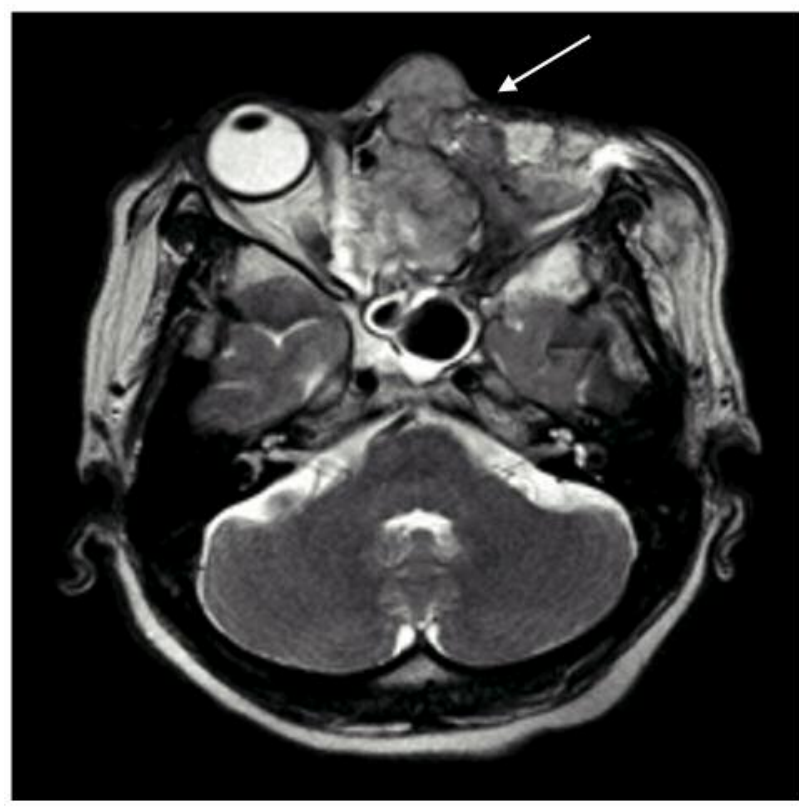

B

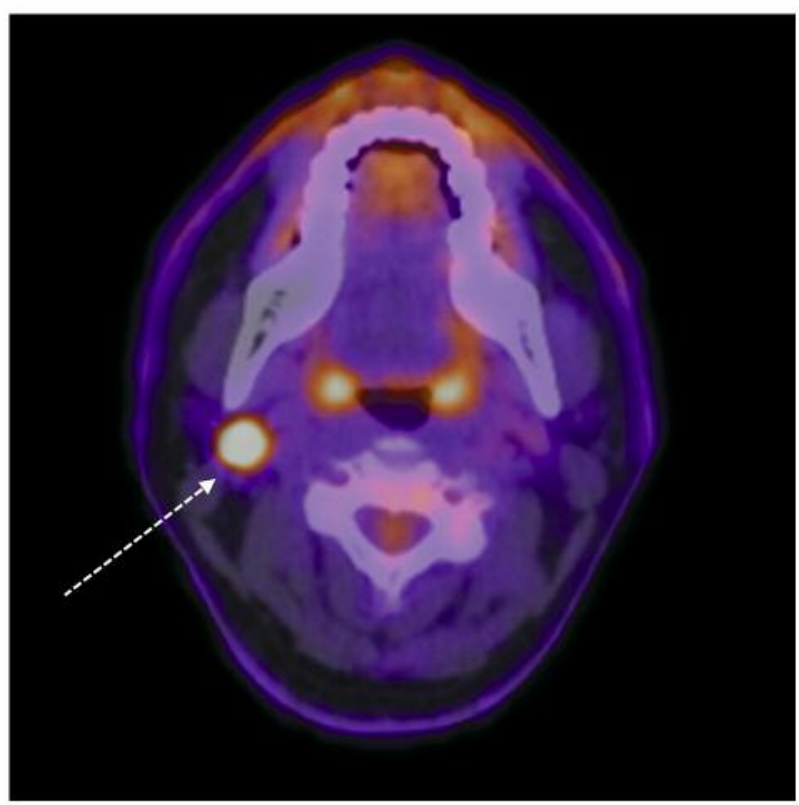

Figure 2. Ethmoid air cell rhabdomyosarcoma in a 27-year-old male. A: Axial T2-weighted magnetic resonance imaging showing an intermediate tumour signal infiltrating the ethmoid sinuses bilaterally and invading the left orbit (arrow). B: Fluorodeoxyglucose (FDG) positron-emission tomography/computed tomography showing a right FDG-avid level 2 lymph node metastasis (arrow). Nodal spread is a recognised feature of rhabdomyosarcoma.

following features were documented: Tumour location, maximum size, presence of pathological nodes (defined as $>1 \mathrm{~cm}$, abnormal enhancement or irregular margins), abnormal fat, calcification and distant metastases at presentation. Superficial STS was considered to be masses arising superficial to the muscle fascia or from superficial muscle fibres. 


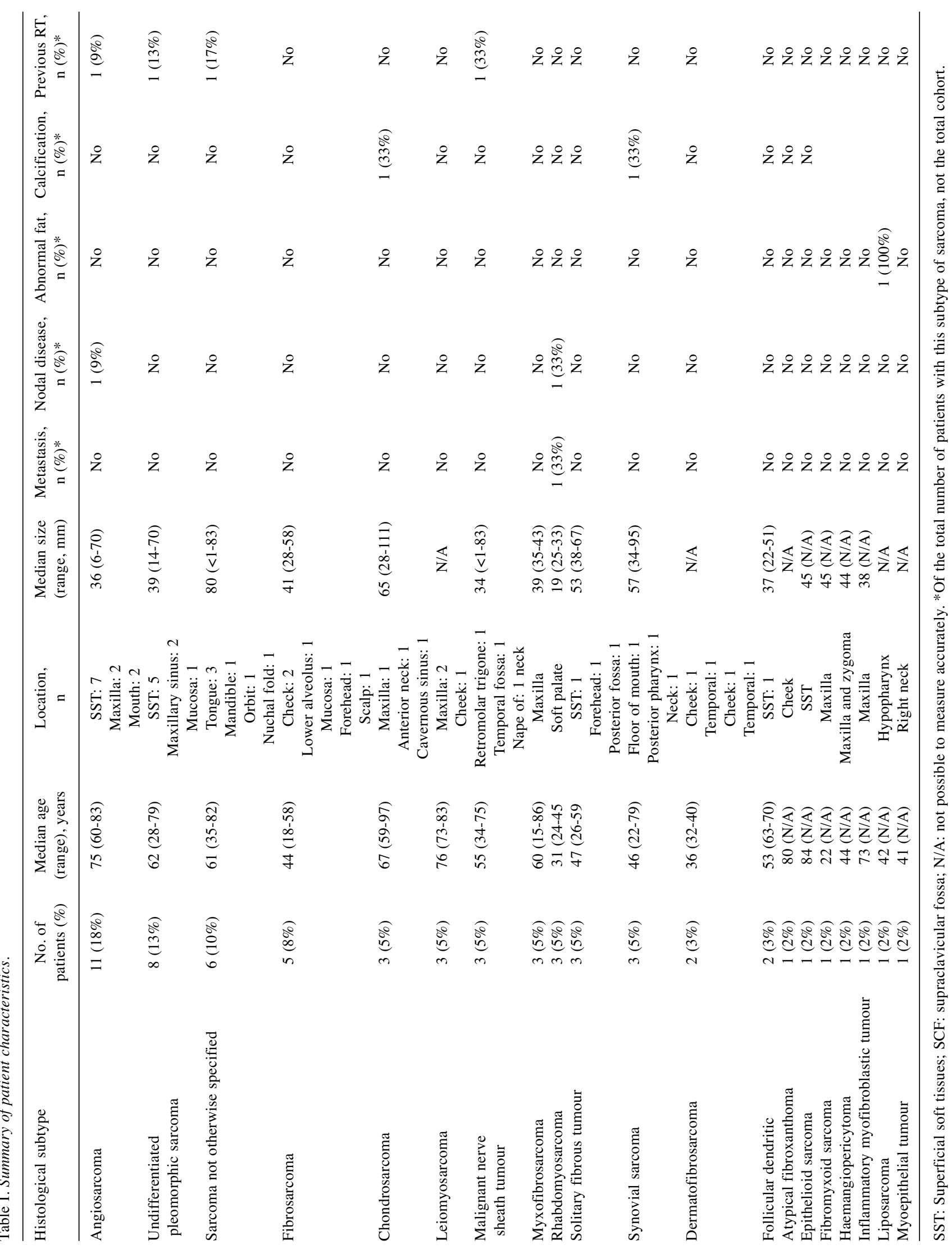


Pathology was reviewed in all cases by an experienced soft-tissue pathologist. Descriptive statistics were used to represent the findings.

\section{Results}

A total of 62 eligible patients were identified. Patient and tumour characteristics are summarized in Table I.

The median age of patients was 60 (range $=15-90)$ years, and the female to male ratio was $1: 1.5$. The commonest sarcomas were angiosarcoma (18\%), undifferentiated pleomorphic sarcoma (UPS) (13\%), sarcoma not otherwise specified (10\%) and fibrosarcoma (8\%) (Table I). The most common locations were superficial craniofacial and neck soft tissues $(58 \%)$, oropharynx $(16 \%)$ and paranasal sinuses $(15 \%)$ (Figure 1). The average size of the primary tumour at presentation was $45 \mathrm{~mm}$ (range $=10-83 \mathrm{~mm}$ ). In addition, in our case series, FDG PET/CT was performed in 10 out of 62 cases $(16 \%)$ but did not result in upstaging.

Nodal disease was identified at presentation in two cases: in one patient with rhabdomyosarcoma (Figure 2) and another with angiosarcoma of the pinna (Figure 3). Calcification was seen in two cases (3\%) (chondrosarcoma and synovial sarcoma) (Figure 4).

Four out of $62(6 \%)$ sarcomas in our case series had a previous history of radiotherapy to the head and neck (angiosarcoma, UPS, MPNST, SNOS) (Table I). One of the four patients with MPNST had a history of NF1 (Figure 5).

\section{Discussion}

This retrospective study confirms that head and neck sarcomas often present as a large, superficial mass with no lymph node involvement, in contrast to squamous cell carcinoma. It is important that these features trigger suspicion for sarcoma particularly as patients are most commonly evaluated by non-sarcoma specialists at initial presentation. Due to the anatomical challenges of the head and neck, early referral to an experienced sarcoma multidisciplinary team is essential in order to provide optimal management. This study is unique as it describes the relative incidence and presentation of head and neck sarcomas at our tertiary sarcoma centre in addition to the imaging appearance of head and neck sarcomas as has been reported by another author (8).

Although generally liposarcoma is the second commonest sarcoma after pleomorphic UPS, it was uncommon in this series of head and neck sarcomas (2\%) (Figure 6).

The commonest head and neck sarcoma in this series was angiosarcoma and more than half were superficial. Superficial angiosarcomas are commonly seen in sun-exposed areas in elderly patients. One patient had a history of radiotherapy 13 years prior for sinonasal malignancy. Previous radiotherapy, typically 5-10 years prior, is a known risk factor for sarcoma

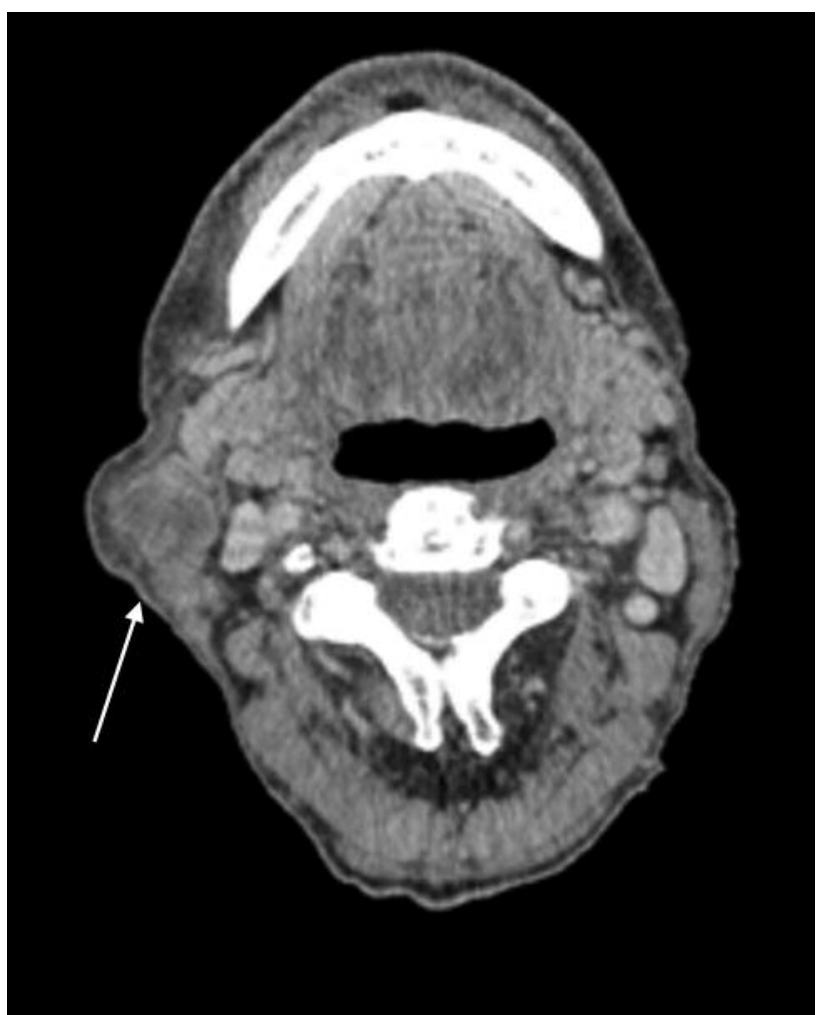

Figure 3. Axial unenhanced computed tomography of the neck of an 80year-old male with angiosarcoma of the pinna showing a right level 2 lymph node metastasis (arrow). Angiosarcoma is one of the few sarcoma subtypes known to spread to lymph nodes.

$(9,10)$. Other risk factors include exposure to vinyl chloride, lymphoedema (Stewart-Treves syndrome) and syndromes including NF1, Klippel-Trénaunay-Weber syndrome, and Maffucci syndrome (10). An association with foreign bodies and immunosuppression are also described (10). Although angiosarcomas generally account for fewer than $1 \%$ of all sarcomas, the head and neck is the most common site and $60 \%$ are reportedly cutaneous (10-12). Alongside imaging of the primary site, clinical photographs reviewed in parallel aid diagnosis and assessment of treatment response. In the early stage, cutaneous angiosarcoma can present as a bruise, or a typically red papule, which may be mistaken for a benign lesion (10). With increasing size, tumour fungation, ulceration and bleeding can occur (10). None of the patients in this series presented with distant metastatic disease, however, pulmonary metastases from angiosarcoma are the commonest form of metastatic disease and can have unusual appearances, including peri-lesional ground-glass change and cavitation (Figure 7), which can lead to a pneumothorax (13).

The second most common type of sarcoma in the head and neck was UPS. UPS are aggressive tumours accounting for 


\section{A}

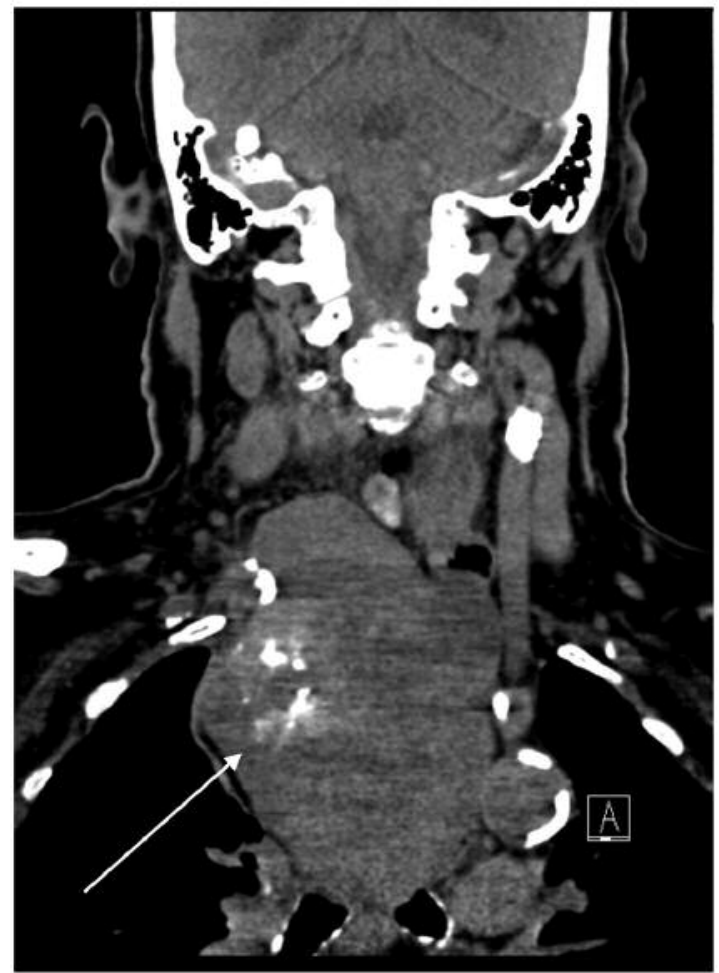

B

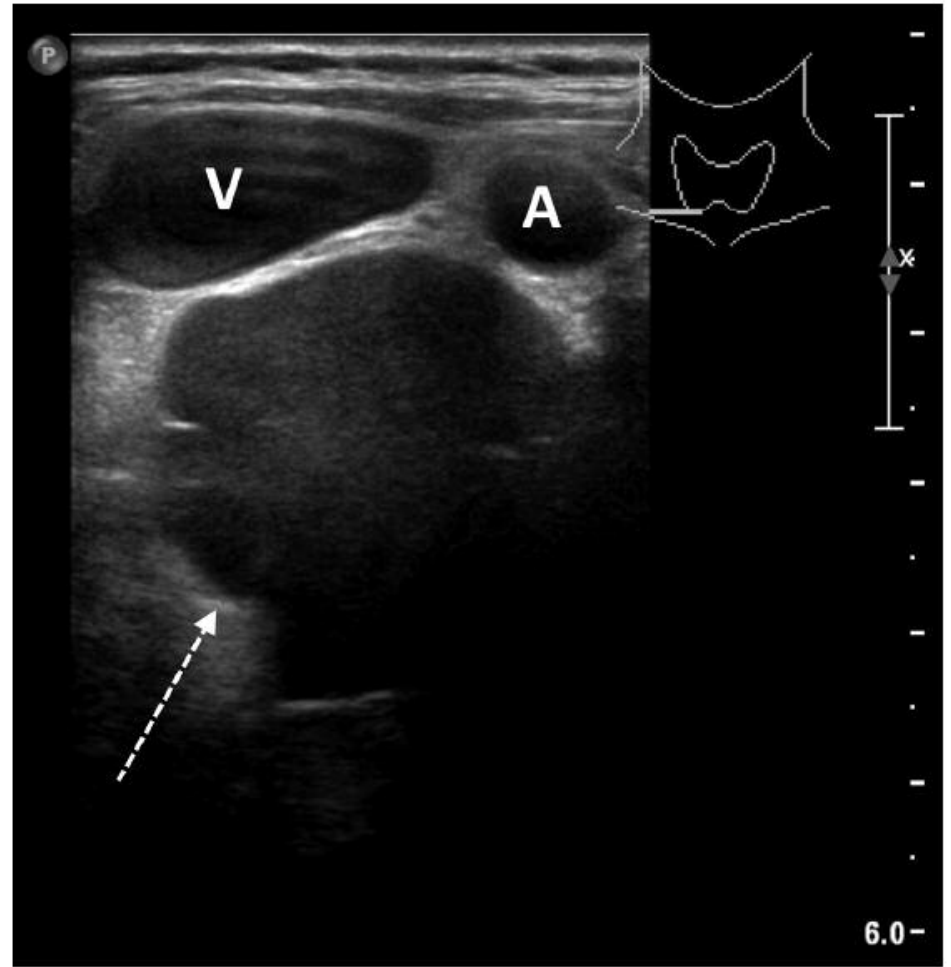

Figure 4. Synovial sarcoma in an 85-year-old female. A: Coronal reformat computed tomography of the neck showing a large soft-tissue mass containing calcifications (arrow). B: Transverse ultrasound image of the neck showing the cystic component (arrow), common carotid artery (A) and vein $(V)$. Cystic change and calcification are recognised features of synovial sarcoma.

A

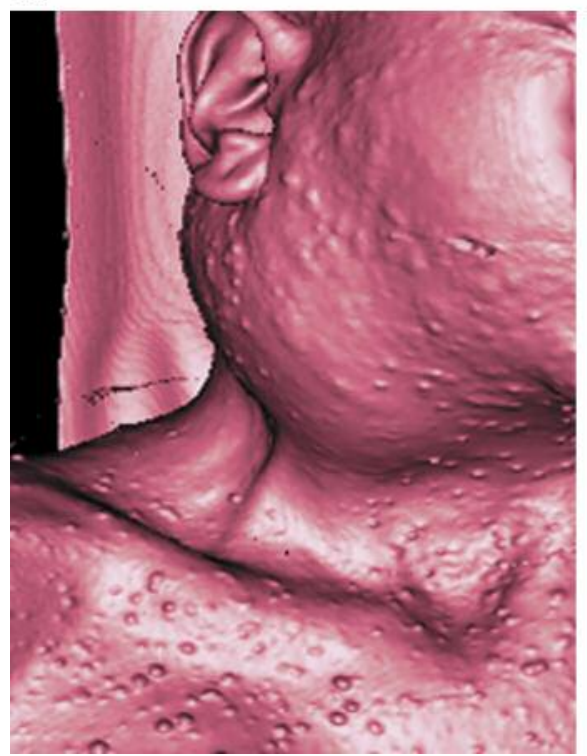

B

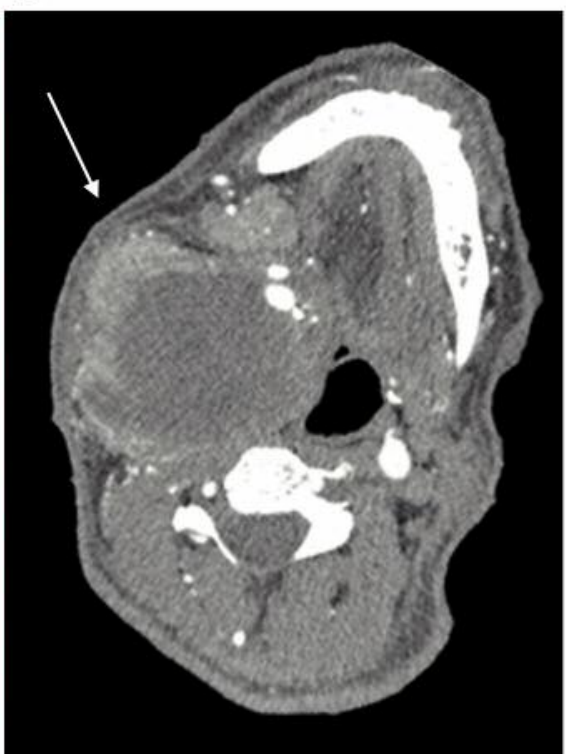

C

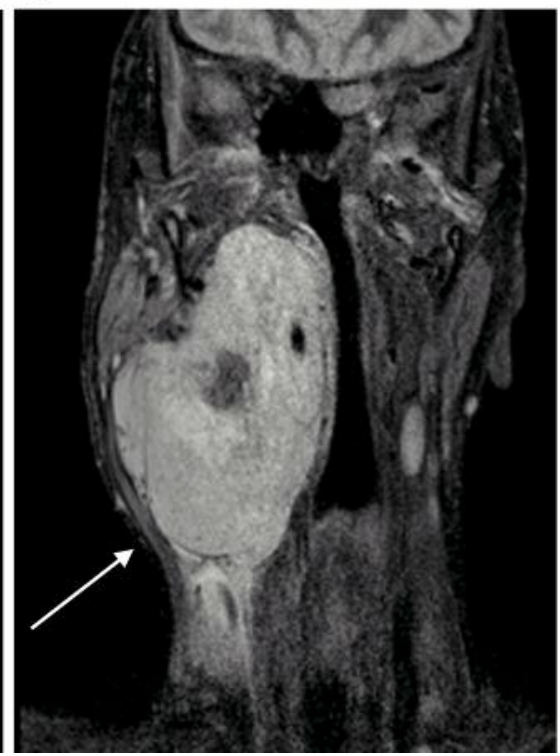

Figure 5. Malignant peripheral nerve sheath tumour in a 31-year-old female. A: A 3D rendered computed tomographic (CT) image showing multiple cutaneous neurofibromas in a patient with neurofibromatosis. Axial $C T(B)$ and coronal T1-weighted magnetic resonance imaging post gadolinium contrast $(C)$ demonstrated a large, partially necrotic mass which was proven by biopsy to be malignant peripheral nerve sheath tumour (arrows). 
A

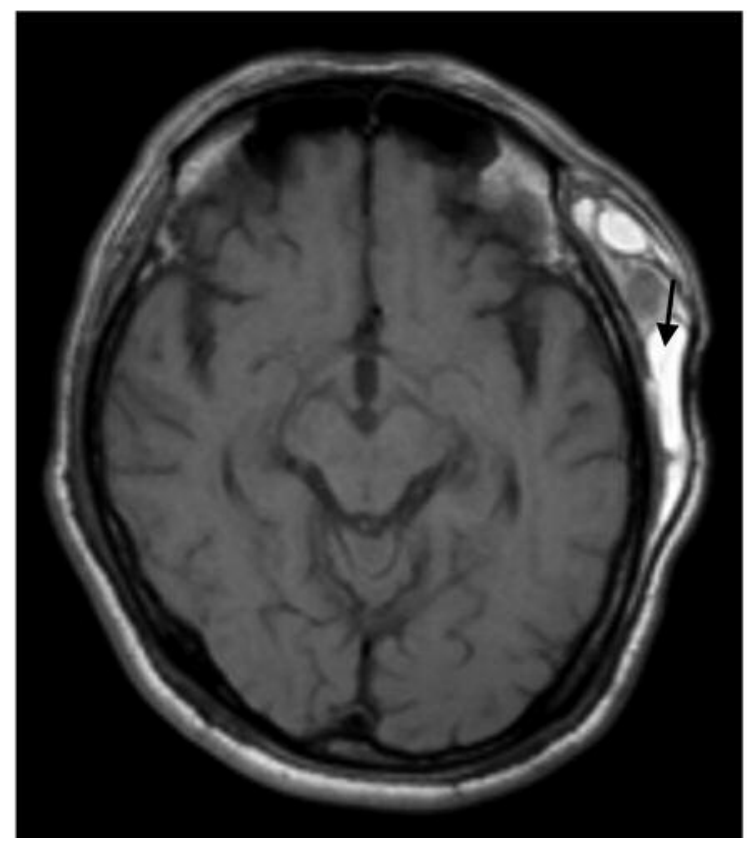

B

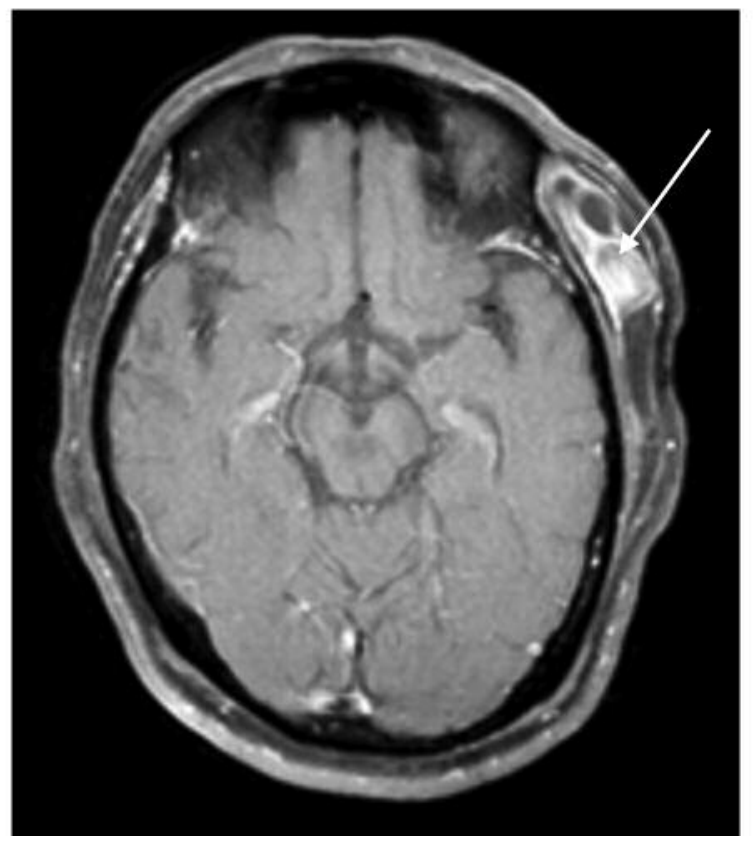

Figure 6. Liposarcoma of the left temporal scalp in a 56-year-old male. A: Fat-suppressed axial T1-weighted magnetic resonance imaging (MRI) showing high signal lipomatous elements (arrow). B: Axial T1-weighted MRI post gadolinium contrast demonstrating solid enhancing elements (arrow), which represent the dedifferentiated component.

A

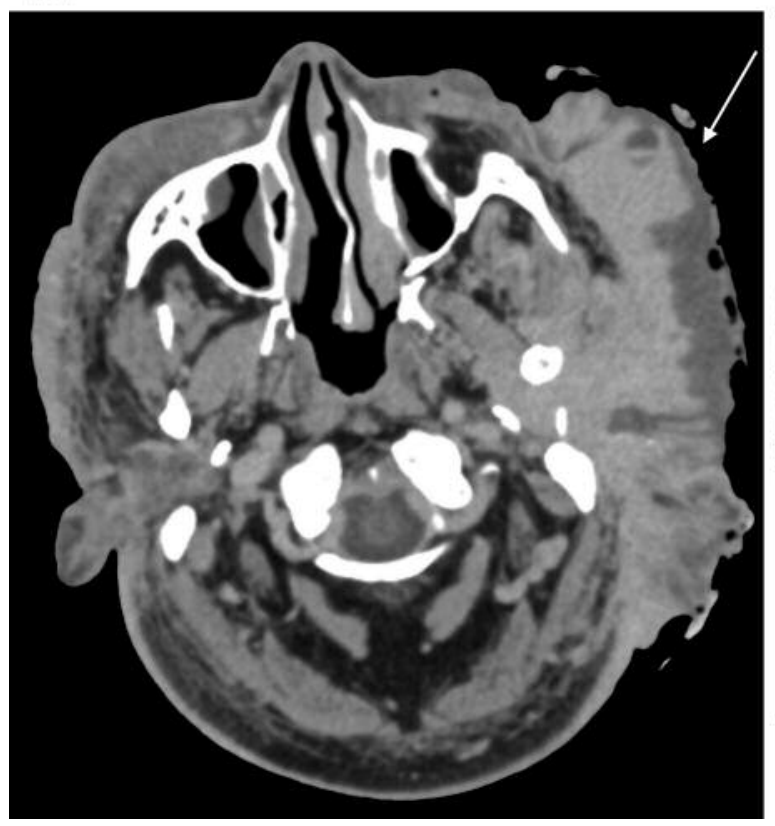

B

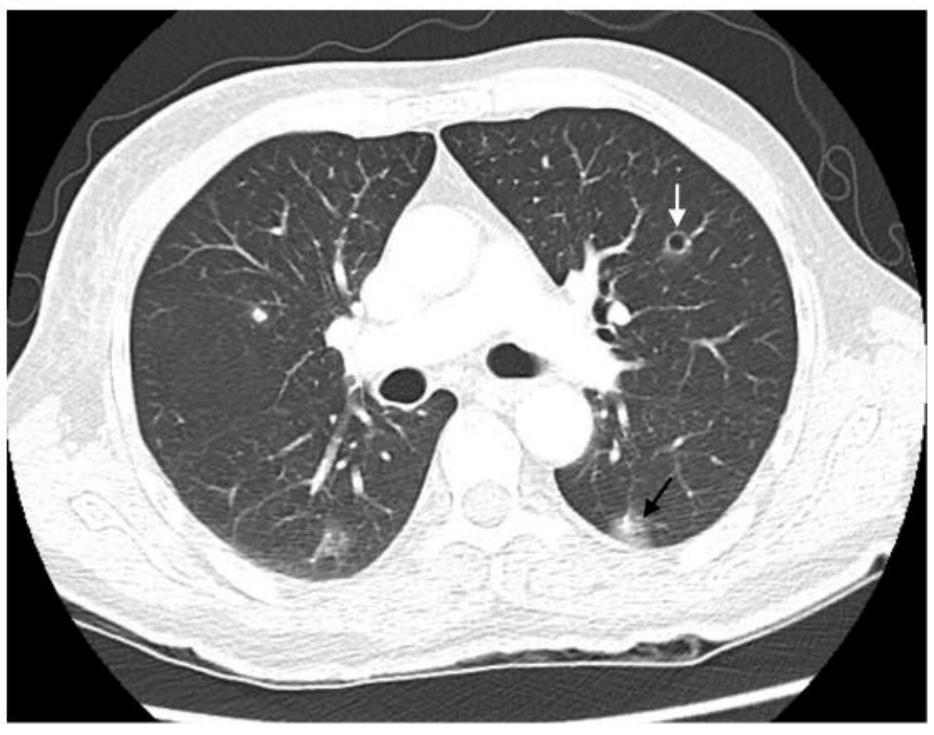

Figure 7. A further example of angiosarcoma of the head and neck. A: Axial computed tomography (CT) of the head with contrast demonstrating a large fungating tumour mass (arrow) in a 64-year-old male. B: Axial CT of the thorax in the same patient at a later date showing development of lung lesions, with classical appearances of angiosarcoma metastases with cavitation (white arrow) and perilesional ground glass change (black arrow). 
$25-40 \%$ of all adult STSs, making them the most common STS (14). Although UPS are typically large and deep tumours, our series indicated that in the head and neck, they are usually superficial. In this series, there was no evidence of metastatic disease at presentation.

The only tumours with calcification were chondrosarcoma and synovial sarcoma, in which calcifications are a wellrecognised feature (15-20). In this series, only two cases, a rhabdomyosarcoma and an angiosarcoma (3\%), had nodal disease at presentation. Sarcoma subtypes with a known propensity for lymph node spread include rhabdomyosarcoma, angiosarcoma, epithelioid, clear-cell and synovial sarcoma $(2,21)$.

One of the three patients with MPNST had NF1, which is a known risk factor for STS. Generally MPNSTs account for $5-10 \%$ of all STSs, with $50 \%$ arising in association with NF1 $(19,20,22-24)$; $8-13 \%$ of patients with NF1 will develop MPNST (22-24). Large masses (>5 cm) or rapid growth of a pre-existing neurofibroma or sudden onset of pain in a patient with NF1 should be regarded as suspicious for malignant transformation, justifying biopsy (25-27). Prior radiation exposure is also a risk factor for MPNST (27).

Squamous cell carcinomas of the head and neck typically arise from the epithelial surfaces of the upper aerodigestive tract and early nodal metastasis, which can be necrotic, is common. The majority of head and neck STSs in our series presented as a superficial large mass without lymphadenopathy as discussed above. These features therefore should raise suspicion for STS diagnosis. Given that up to $3 \%$ of sarcomas in general can arise in areas of previous irradiation (28), masses arising within a radiation field should also raise concern for a sarcoma diagnosis. A known history of NF1 is also relevant (25). It should be noted that accurate sarcoma diagnosis rests on core biopsy, and excision biopsy is to be avoided owing to the potential disruption of soft-tissue planes. Although STS of the head and neck can be difficult to diagnose, knowledge of some of the key imaging characteristics may trigger suspicion for a diagnosis of STS and referral to a specialist STS centre for investigation including biopsy.

\section{Conflicts of Interest}

The Authors have no conflicts of interest to declare relevant to the above publication.

\section{Authors' Contributions}

Study Concept: CM. Data collection and analysis: AJ, PT, DA, AW, CM. Article preparation and review: All Authors.

\section{Acknowledgements}

The Authors acknowledge National Health Service funding to the National Institute for Health Research (https://www.nihr.ac.uk/)
Biomedical Research Centre, Clinical Research Facility in Imaging and the Cancer Research Network. This report is independent research funded by the National Institute for Health Research. The views expressed in this publication are those of the Authors and not necessarily those of the National Health Service, the National Institute for Health Research or the Department of Health.

\section{References}

1 Cancer Research UK: Soft-tissue sarcomas, risks and causes, 2015. Available at: https://www.cancerresearchuk.org/aboutcancer/soft-tissue-sarcoma/risks-causes

2 Razek AA and Huang BY: Soft-tissue tumors of the head and neck: Imaging-based review of the who classification. Radiographics 31(7): 1923-1954, 2011. PMDI: 22084180. DOI: 10.1148/rg.317115095

3 van Vliet M, Kliffen M, Krestin GP and van Dijke CF: Soft-tissue sarcomas at a glance: Clinical, histological, and MR imaging features of malignant extremity soft-tissue tumors. Eur Radiol 19(6): 1499-1511, 2009. PMID: 19266204. DOI: 10.1007/s00330008-1292-3

4 World Health Organisation: Pathology and Genetics, Tumours of Soft Tissue and Bone. IARC Press: Lyon, pp. 1-308, 2002.

5 De Schepper AM and Bloem JL: Soft-tissue tumors: Grading, staging, and tissue-specific diagnosis. Top Magn Reson Imaging 18(6): 431-444, 2007. PMID: 18303401. DOI: 10.1097/rmr. 0b013e 3181652220

6 Hahn E, Huang SH, Hosni A, Razak AA, Jones RL, Dickson BC, Sturgis EM, Patel SG and O'Sullivan B: Ending 40 years of silence: Rationale for a new staging system for soft-tissue sarcoma of the head and neck. Clin Transl Radiat Oncol 15: 1319, 2019. PMID: 30582016. DOI: 10.1016/j.ctro.2018.11.009

7 American Joint Committee on Cancer (AJCC): AJCC Cancer Staging Manual, Eighth Edition. Mahul B. Amin (ed.). Springer: New York, 2017.

8 Scelsi CL, Wang A, Garvin CM, Bajaj M, Forseen SE and Gilbert BC: Head and neck sarcomas: A review of clinical and imaging findings based on the 2013 World Health Organization Classification. Am J Roentgenol 212(3): 644-654, 2019. PMDI: 30589383. DOI: $10.2214 /$ AJR.18.19894

9 Huang J and Mackillop WJ: Increased risk of soft-tissue sarcoma after radiotherapy in women with breast carcinoma. Cancer 92(1): 172-180, 2001. PMDI: 11443624. DOI: 10.1002/10970142(20010701)92:1<172::aid-cncr1306>3.0.co;2-k

10 Young RJ, Brown NJ, Reed MW, Hughes D and Woll PJ: Angiosarcoma. Lancet Oncol 11(10): 983-991, 2010. PMDI: 20537949. DOI: 10.1016/S1470-2045(10)70023-1

11 Mark RJ, Poen JC, Tran LM, Fu YS and Juillard GF: Angiosarcoma. A report of 67 patients and a review of the literature. Cancer 77(11): 2400-2406, 1996. PMID: 8635113. DOI: $10.1002 /(\mathrm{SICI}) 1097-0142(19960601) 77: 11<2400:$ AIDCNCR32>3.0.CO;2-Z

12 Aust MR, Olsen KD, Lewis JE, Nascimento AG, Meland NB, Foote RL and Suman VJ: Angiosarcomas of the head and neck: Clinical and pathologic characteristics. Ann Otol Rhinol Laryngol 106(11): 943-951, 1997. PMID: 9373085. DOI: $10.1177 / 000348949710601110$

13 Tateishi U, Hasegawa T, Kusumoto M, Yamazaki N, Iinuma G, Muramatsu Y and Moriyama N: Metastatic angiosarcoma of the 
lung: Spectrum of CT findings. Am J Roentgenol 180(6): 16711674, 2003. PMDI: 12760941. DOI: 10.2214/ajr.180.6.1801671

14 Kransdorf MJ: Malignant soft-tissue tumors in a large referral population: Distribution of diagnoses by age, sex, and location. Am J Roentgenol 164(1): 129-134, 1995. PMDI: 7998525. DOI: 10.2214/ajr.164.1.7998525

15 Weiss SW and Goldblum JR: Malignant tumors of uncertain type. In: Soft-Tissue Tumors, Sixth Edition. Enzinger FM and Weiss SW (eds.). Mosby, 2013. ISBN: 9780323088343.

16 Kransdorf MJ and Murphey MD: Synovial tumours. In: Lippincott Williams \& Wilkins, pp. 381-436, 2005. ISBN-10: 0781747716.

17 Murphey MD, Walker EA, Wilson AJ, Kransdorf MJ, Temple HT and Gannon FH: From the archives of the AFIP: Imaging of primary chondrosarcoma: Radiologic-pathologic correlation. Radiographics 23(5): 1245-1278, 2003. PMDI: 12975513. DOI: $10.1148 / \mathrm{rg} .235035134$

18 Weiss SW and Goldblum JR: Malignant fibrohistiocytic tumors. In: Soft-tissue Tumors, Sixth Edition. Enzinger FM and Weiss SW (eds.). Mosby, 2013. ISBN: 9780323088343.

19 Kransdorf MJ and Murphey MD: Neurogenic tumors. In: Imaging of Soft-tissue Tumors, Second Edition. Lippincott Williams \& Wilkins pp. 328-380, 2005.

20 Weiss SW and Goldblum JR: Malignant tumors of the peripheral nerves. In: Soft-tissue Tumors, Sixth Edition. Enzinger FM and Weiss SW (eds.). Mosby, 2013. ISBN: 9780323088343.

21 Wang H, Miao R, Jacobson A, Boyd G, Goldberg S, Mitra D, Cote GM, Choy E, Hornicek FC, Raskin K, DeLaney TF and Chen Y: Nodal involvement and survival in synovial, clear cell, angio-, rhabdo-, and epithelioid sarcoma. J Clin Oncol 36, no. 15_suppl: 11567-11567, 2018. DOI: 10.1200/JCO.2018.36. 15_suppl.11567

22 Rodriguez FJ: Peripheral nerve sheath tumors: The elegant chapter in surgical neuropathology. Acta Neuropathol 123(3): 293-294, 2012. PMDI: 22311741. DOI: 10.1007/s00401-0120955-y
23 Foley KM, Woodruff JM, Ellis FT and Posner JB: Radiationinduced malignant and atypical peripheral nerve sheath tumors. Ann Neurol 7(4): 311-318, 1980. PMDI: 7377756. DOI: 10.1002/ana.410070405

24 LaFemina J, Qin LX, Moraco NH, Antonescu CR, Fields RC, Crago AM, Brennan MF and Singer S: Oncologic outcomes of sporadic, neurofibromatosis-associated, and radiation-induced malignant peripheral nerve sheath tumors. Ann Surg Oncol 20(1): 66-72, 2013. PMDI: 22878618. DOI: 10.1245/s10434012-2573-2

25 Evans DG, Baser ME, McGaughran J, Sharif S, Howard E and Moran A: Malignant peripheral nerve sheath tumours in neurofibromatosis 1. J Med Genet 39(5): 311-314, 2002. PMDI: 12011145. DOI: $10.1136 /$ jmg.39.5.311

26 Kransdorf MJ and Murphey MD: Malignant fibrous and fibrohistiocytic tumors. In: Imaging of Soft-tissue Tumors, Second Edition. Lippincott Williams \& Wilkins pp. 257-297, 2005.

27 Ducatman BS, Scheithauer BW, Piepgras DG, Reiman HM and Ilstrup DM: Malignant peripheral nerve sheath tumors. A clinicopathologic study of 120 cases. Cancer 57(10): 2006-2021, 1986. PMDI: 3082508. DOI: 10.1002/1097-0142(19860515) 57:10<2006::aid-cncr2820571022>3.0.co;2-6

28 Yap J, Chuba PJ, Thomas R, Aref A, Lucas D, Severson RK and Hamre M: Sarcoma as a second malignancy after treatment for breast cancer. Int J Radiat Oncol Biol Phys 52(5): 1231-1237, 2002. PMDI: 11955733. DOI: 10.1016/s0360-3016(01)02799-7

Received August 28, 2019 Revised September 26, 2019 Accepted October 1, 2019 